\title{
Antifungal activity of the essential oil isolated from Laurus nobilis L. against Cryptococcus neoformans strains
}

\author{
Lílian Sousa Pinheiro $^{1^{*}}$, Abrahão Alves de Oliveira Filho ${ }^{2}$, Felipe Queiroga Sarmento Guerra ${ }^{1}$, Camilla Pinheiro de \\ Menezes ${ }^{1}$, Socrates Golzio dos Santos ${ }^{3}$, Janiere Pereira de Sousa ${ }^{1}$, Tassiana Barbosa Dantas ${ }^{1}$, Edeltrudes de Oliveira \\ Lima $^{1}$
}

${ }^{1}$ Program in Natural Products and Synthetic Bioactive, Federal University of Paraiba, Paraiba, Brazil.

${ }^{2}$ Academic Unit Biological Sciences, Federal University of Campina Grande, Paraiba, Brazil.

${ }^{3}$ Research Institute for Drugs and Medicines, Federal University of Paraiba, Paraiba, Brazil.

\begin{tabular}{|c|c|}
\hline ARTICLE INFO & ABSTRACT \\
\hline $\begin{array}{l}\text { Article history: } \\
\text { Received on: } 04 / 07 / 2016 \\
\text { Accepted on: } 08 / 12 / 2016 \\
\text { Available online: } 30 / 05 / 2017\end{array}$ & $\begin{array}{l}\text { Cryptococcosis is an opportunistic fungal infection that evolved to an important cause of morbidity and } \\
\text { mortality in recent years. Even with advances in medicine, the treatment of ringworm still presents a therapeutic } \\
\text { system with limited availability of antifungal agents, and so, research is needed to identify new agents } \\
\text { fungistatic or fungicides effectives. The natural products are known to represent an arsenal of compounds, some }\end{array}$ \\
\hline $\begin{array}{l}\text { Key words: } \\
\text { Essential oil, antifungal, } \\
\text { Cryptococcus, Laurus } \\
\text { nobilis. }\end{array}$ & $\begin{array}{l}\text { of Laurus nobilis L. (leaves) against Cryptococcus neoformans strains. The chemical composition of the oil was } \\
\text { analyzed by gas chromatography coupled to mass spectrometry (GC / MS) and minimum inhibitory } \\
\text { concentration (MIC) and the minimum fungicidal concentration (MFC) were determined by the broth micro } \\
\text { dilution techniques. The MIC } 100 \text { of essential oil were } 256 \mu \mathrm{g} / \mathrm{mL} \text { and the } \mathrm{MFC}_{50} \text { was } 1024 \mu \mathrm{g} / \mathrm{mL} \text {. In } \\
\text { conclusion the essential oil showed in vitro antifungal potential against strains of } C \text {. neoformans. }\end{array}$ \\
\hline
\end{tabular}

\section{INTRODUCTION}

Cryptococcosis is an opportunistic fungal infection that has featured between mycoses due to its high incidence in patients with Acquired Immunodeficiency Syndrome (AIDS), and the difficulties of treatment, high mortality in humans and animals with nervous system involvement central.Cryptococcus neoformans is a major etiological agents of cryptococcosis, and has the ability to infect healthy individuals and with impaired cellular immunity (Chayakulkeeree and Perfect 2006; Dromer et al., 2004; Mirza et al., 2003; Pukkila-Worley and Mylonakis, 2008; Singh et al., 2008). Since the treatment this mycosis, involves a therapeutic system with limited antifungal agents, some of these, with high toxicity and microbial resistance (Girois et al., 2006). Among the antifungal agents are used amphotericin

\footnotetext{
* Corresponding Author

Lilian Sousa Pinheiro, Programin Natural Products and Synthetic Bioactive, Federal University of Paraiba, Paraiba, Brazil.

Email: lilianspinheiro@hotmail.com
}

B, flucytosine and fluconazole or itraconazole administered in combination or individually. At the beginning of treatment can be used Amphotericin B associated with flucytosine, where for more prolonged treatment is recommended the use of fluconazole (Saag et al., 2000). The medicinal and aromatic plants have been the subject of various studies in order to find biologically effective compounds with lower toxicity and which can possibly be used to treat various types of infectious diseases (Nakamura et al., 2004; Oliveira et al. 2006; Prabuseenivasan; Jayakumar; Ignacimuthu, 2006; Saad, 2010). Essential oils are produced from the secondary metabolism of plants and considered important in various functions necessary for the survival of the plant, as a defense mechanism against microorganisms (Gonçalves et al., 2003; Siqui et al., 2000). Since ancient times, they are known through its antibacterial and antifungal properties (Cavaleiro et al., 2006; Cowan, 1999; Tenpone et al., 2008). Laurus nobilis L. is a small aromatic plant belonging to the family Lauraceae, popularly known as laurel. It is widely used by the food industry, pharmaceuticals and cosmetics. 
The dried leaves are considered important ingredients in food preparation, and the essential oil is a valuable complement in the aroma of various types of food, especially meat, sausages, canned soups and bakery products (Patrakar; Mansuriy; Patil, 2012).

The antimicrobial properties and insecticides have made the use of this common plant for preserving food by the food industry. In folk medicine, it is used in rheumatic processes, dermatitis, gastrointestinal disorders such as epigastric distention, and flatulence impaired digestion. The aqueous extract is commonly used as antihaemorrhoidal, antirheumatic, diuretic, antidote for snake bites and for the treatment of stomach pains (Baytop, 1984; Gulcin, 2006).

Because the clinical and epidemiological importance of cryptococcosis, further investigations are necessary to contribute with safer treatment options, low cost for the population, assessing the chances of successful treatment.Therefore, the search for less toxic antifungal agents and products derived from medicinal plants is vital and considered an excellent alternative for this purpose. The objective of this study was to investigate the antifungal activity in vitro of the essential oil of Laurus nobilis L. (leaves) against strains of $C$. neoformans.

\section{MATERIALS AND METHODS}

\section{Essential Oil}

The essential oil of L. nobilis L. was purchased from Company Quinari ${ }^{\circledR}$ House of Essences (Ponta Grossa, Parana, Brazil), being extracted from the leaves by steam distillation. This product has met the purity requirements specified by the Food and Agriculture Organization (FAO) and the World Health Organization (WHO) on food additives and their quality parameters were described in a technical bulletin sent by the company.

The essential oil was solubilized in $5 \%$ dimethylsulfoxide (DMSO) and 2\% Tween 80. Next, sterile distilled water was added and the tubes mixed for 5 min using a Vortex (Fanem), to obtain the desired concentration.

\section{Fungal strains}

For antifungal activity assays, were selected strains of $C$. neoformans: FCF10, LM 0109, LM 310, LM 2601, LM 2301, LM 1909and LM 0310. All the microorganisms were obtained of collection of Laboratory of Mycology, Federal University of Paraiba - Brazil.Fungi were maintained on Sabourad Dextrose Agar (SDA) (Difco Lab., USA)inclined at $4{ }^{\circ} \mathrm{C}$. Inoculums were obtained from fresh cultures of each of the selected strains of $C$. neoformans, previously grown in sterile tubes containing tilted Sabouraud dextrose agar (SDA; Difco Lab., USA), incubated at 37 ${ }^{\circ} \mathrm{C}$ for 72 hours.

Colonies of this culture were suspended in sterile $0.85 \%$ $\mathrm{NaCl}$ to provide a final concentration of approximately $10^{6}$ count forming unit per $\mathrm{mL}\left(\mathrm{CFU} \cdot \mathrm{mL}^{-1}\right)$ adjusted according to the turbidity of $0.5 \mathrm{McF}$ arland scale tube.

\section{Standard antifungal}

Flucytosine (Sigma-Aldrich®, São Paulo-SP) was used as the standard antifungal.

\section{Essential oil analysis}

The sample was analyzed with a SHIMADZU GC/MS QP2010 Ultra gas chromatographer coupled to a mass spectrometer with highly purified helium as the carrier gas. An aliquot of $1 \mu \mathrm{L}$ of the prepared sample solution was injected in split mode in ratio 1:20 with a purge time of $3 \mathrm{~min}$. The injection ports, the GC to MS transfer line and ion source temperatures were held at $250{ }^{\circ} \mathrm{C}$. A $30 \mathrm{~m}$ long RTX-5 MS column (25.0 $\mu \mathrm{m}$ i.d.; and $0.25 \mu \mathrm{m}$ film thickness; Restek Corporation) was used to separate all the target compounds. The GC oven temperature program was as follows: $60{ }^{\circ} \mathrm{C}, 3{ }^{\circ} \mathrm{C} / \mathrm{min}$ to $240{ }^{\circ} \mathrm{C}$.

\section{Determination of minimal inhibitory concentration (MIC)}

MIC of the essential oil was determined by the microdilution technique in broth medium (Cleeland; Squires, 1991; Eloff, 1998; Hadacek and Greger, 2000). Cultures of $C$. neoformans were seeded in SDA and incubated at $35^{\circ} \mathrm{C}$ for $24-72$ h. Colonies of this culture were suspended in sterile $0.85 \% \mathrm{NaCl}$ and the inoculum was standardized at 0.5 tube of McFarland scale $\left(10^{6} \mathrm{CFU} \mathrm{mL}^{-1}\right)$. Sabouraud dextrose broth (Difco Lab., USA) was added to all wells of 96-well plates. Next, serial dilutions were made to obtain concentrations varying between 1 and $1024 \mu \mathrm{g} . \mathrm{mL}^{-}$ 1 . The same procedure was carried out with flucytosine. DMSO (5\%) and Tween $80(2 \%)$, without drugs, serving as the negative control to verify the absence of interference on fungal growth. Finally, $10 \mu \mathrm{L}$ of yeast inoculum were added to all wells, and the plates were incubated at $35^{\circ} \mathrm{C}$ for $24-72 \mathrm{~h}$. The test was performed in duplicate. MIC was defined as the lowest concentration capable of visually inhibiting fungal growth seen in the wells (Souza et al., 2007).

\section{Determination of minimal fungicidal concentration (MFC)}

Aliquots of $10 \mu \mathrm{L}$ of supernatant from each well of the microtiter plate with no visible fungal growth were subcultured on dextrose saubourad agar plates, devoid of any antifungal. The plates were incubated at $35^{\circ} \mathrm{C}$ for $24-72 \mathrm{~h}$. MFC was defined as the lowest concentration of essential oil that caused total inhibition of visible growth (Espinel-Ingroff et al., 2002;Ernst et al., 2002; Pereira et al., 2011a; Trajano et al., 2010). The test was performed in duplicate.

\section{RESULTS AND DISCUSSION}

The essential oil of L. nobilis L., obtained by steam distillation, was analyzed by gas chromatography-mass spectrometry (GC-MS). The predominant component identified was isoeugenol $(57 \%)$, followed by myrcene $(15.9 \%)$, chavicol 
$(9.3 \%)$ and methyl eugenol $(2.43 \%)$ (Table 1$)$. The main constituents of the essential oil of $L$. nobilis L. leaves are referred to in the literature as 1.8 -cineole, terpineol, $\beta$-pinene, $\alpha$-pinene, $\mathrm{p}$ cymene, $\beta$-caryophyllene. The acyclic monoterpenes (linalool and myrcenol) may also be present, as well as, dimethyl styrene, eugenol, methyl eugenol and carvacrol (Riaz et al., 1989; Rizi, 2008, 2009; Rosa and Assunta, 2008; Yalcin et al., 2007).

Table 1: Essential oil components from the leaves of L. nobilis L.

\begin{tabular}{ccccc}
\hline Peak & $\begin{array}{c}\text { Time to } \\
\text { retention } \\
(\mathbf{m i n})\end{array}$ & Constituent & $\begin{array}{c}\text { \% the } \\
\text { sample }\end{array}$ & $\begin{array}{c}\text { Basis } \\
\mathbf{m} / \mathbf{z}\end{array}$ \\
\hline 16 & 23,137 & Isoeugenol & 57,0 & 164,15 \\
4 & 7,556 & Myrcene & 15,9 & 93,10 \\
15 & 18,401 & Chavicol & 9,3 & 134,15 \\
18 & 25.029 & Methyl eugenol & 2,43 & 178,15 \\
11 & 11,568 & Linalool & 2,14 & 71,10 \\
19 & 25,688 & Caryophyllene & 2,10 & 93,10 \\
8 & 8,883 & Limonene & 2,02 & 68,10 \\
Others & - & - & 9,11 & - \\
\hline
\end{tabular}

Analyzes of the MIC values of $L$. nobilis L.essential oil on strains of $C$. neoformans showed that all strains submitted to biological assays had their growth inhibition in a concentration of $256 \mu \mathrm{g} . \mathrm{mL}^{-1}$ of L. nobilis L.essential oil.The $\mathrm{MIC}_{100}$ (MIC for $100 \%$ of the strains tested) was $256 \mu \mathrm{g} \cdot \mathrm{mL}^{-1}$ (Table 2).

Table 2: MIC of the essential oil components from the leaves of L. nobilis L against $C$. neoformans strains.

\begin{tabular}{cccc}
\hline $\begin{array}{c}\text { Substance/ } \\
\text { Fungal } \\
\text { strains }\end{array}$ & $\begin{array}{c}\text { Essential oil MIC } \\
(\boldsymbol{\mu g} / \mathbf{m L})\end{array}$ & $\begin{array}{c}\text { Flucytosine } \\
\mathbf{M I C} \\
(\boldsymbol{\mu g} / \mathbf{m L})\end{array}$ & $\begin{array}{c}\text { Negative } \\
\text { control }\end{array}$ \\
\hline FCF 10 & 256 & 32 & - \\
LM 0109 & 256 & 32 & - \\
LM 310 & 256 & 64 & - \\
LM 0310 & 256 & 32 & - \\
LM 2601 & 256 & 32 & - \\
LM 2301 & 256 & 64 & - \\
LM 1909 & 256 & 128 & - \\
\hline
\end{tabular}

(-) No inhibition.

The flucytosine (positive control) exerted inhibitory effects against all strains tested. The MIC values of antifungal ranged from $32-128 \mu \mathrm{g} . \mathrm{mL}^{-1}$, with $50 \%$ of the strains tested inhibiting $32 \mu \mathrm{g} \cdot \mathrm{mL}^{-1}$. The $\mathrm{MIC}_{50}$ value for the antifungal used in the study was lower than those found by Pfaller et al. (1990) against strains of $C$. neoformans that exhibited MIC values greater than $64 \mu \mathrm{g} \cdot \mathrm{mL}^{-1}$.

According to the literature results is considered strong antifungal activity MIC values between $0.05-0.50 \mathrm{mg} / \mathrm{mL}$, MIC values between 0.6 to $1.50 \mathrm{mg} / \mathrm{mL}$ are considered moderately active and values MIC greater than $1.50 \mathrm{mg} / \mathrm{mL}$ are related to a weak antifungal activity (Sartoratto et al., 2004). The results showed that the essential oil used in this study showed strong activity against $C$. neoformans strains with $\mathrm{MIC}_{100} 256 \mu \mathrm{g} . \mathrm{mL}$ 1.These results are in agreement with the data obtained by Ozcan et al. (2010) in their study using the L. nobilis L. essential oil against various strains of Candida. Analyzing the results of the $\mathrm{MFC}_{50}$ can be seen that the essential oil (Table 3) does have fungistatic activity against $C$. neoformans species, because when when the ratios MFC / MIC was greater than 1 or 2, indicating that the effect of the compound was fungistatic in nature (and not fungicide) (Hafidh et al., 2011).

Table 3: MIC and MFC of the essential oil components from the leaves of $L$. nobilis L againstC. neoformans strains.

\begin{tabular}{ccc}
\hline $\begin{array}{c}\text { Substance/ } \\
\text { Fungal strains }\end{array}$ & MIC $(\boldsymbol{\mu g} / \mathbf{m L})$ & $\begin{array}{c}\text { MFC } \\
(\boldsymbol{\mu g} / \mathbf{m L})\end{array}$ \\
\hline FCF 10 & 256 & 512 \\
LM 0109 & 256 & 1024 \\
LM 310 & 256 & 1024 \\
LM 0310 & 256 & 512 \\
LM 2601 & 256 & 1024 \\
LM 2301 & 256 & 1024 \\
LM 1909 & 256 & 512 \\
\hline
\end{tabular}

\section{CONCLUSION}

Thus, the essential oil of $L$. nobilis $L$ represents a natural product with potential antifungal activity against $C$. neoformans. In the study, the essential oil showed a fungistatic effect. Therefore, the test product is presented as a relevant antifungal and may be contributing to the existing arsenal of products with proven antifungal activity against $C$. neoformans.

Financial support and sponsorship: Nil.

Conflict of Interests: There are no conflicts of interest.

\section{REFERENCES}

Baytop T.Therapy with Medicinal Plants in Turkey. Publications of Istanbul University, Istanbul, 1984, p. 194.

Cavaleiro C, Pinto E, Gonçalves MJ, Salgueiro L. Antifungal activity of Juniperus essential oils against dermatophyte, Aspergillus and Candida strains. Journal of Applied Microbiology, 2006; 100(6); 13331338.

Chayakulkeeree M, Perfect JR. Cryptococcosis. Infectious Disease Clinics of North America, 2006; 20; 507-544.

Cleeland R, Squires E. Evaluation of new antimicrobials in vitro and experimental animal infection In: LORIAN, V. Antibiotics in laboratory medicine. 3. ed. Baltimore: Williams and Wilkins, 1991;739787.

Cowan MM. Plant products as antimicrobial agents. Clinical Microbiology Reviews, 1999; 12(4); 564-582.

Dromer F, Mathoulin-Pélissier S, Fontanet A, Ronin O, Dupont B, Lortholary O. Epidemiology of HIV-associated cryptococcosis in France (1985-2001): comparison of the pre- and post-HAART eras. AIDS, 2004; 18(3); 555-562.

Eloff JN. A sensitive and quick microplate method to determine the minimal inhibitory concentration of plant extracts for bacteria. Planta Medica, 1998; 64(8); 711-713.

Ernst EJ, Roling EE, Petzold CR, Keele DJ, Klepser ME. In Vitro Activity of Micafungin (FK-463) against Candida spp.: Microdilution, Time-Kill, and Postantifungal-Effect Studies. Antimicrobial agents and chemotherapy, 2002; 46(12); 3846-3853.

Espinel-Ingroff A, Fothergill A, Peter J, Rinaldi MG, Walsh TJ. Testing conditions for determination of, minimum fungicidal concentrations of new and established antifungal agents for Aspergillus spp: NCCLS collaborative study. Journal of Clinical Microbiology; 2002; 40(9); 3204-3208 
Girois SB, Chapuis F, Decullier E, Revol BG. Adverse effects of antifungal therapies in invasive fungal infections: review and metaanalysis. European Journal of Clinical Microbiology and Infectious Diseases, 2006; 25(2); 138-149.

GonçalvesLA, Barbosa LCA, Azevedo AAA, Casali VWD, Nascimento EA. Produção e composição do óleo essencial de Alfavaquinha (Ocimim selloi Benth) em resposta a dois níveis de radiação solar. Revista Brasileira de Plantas Medicinais, 2003; 6(1);8-14.Gulcin I. Toxicology; 2006, 213.

Hafidh RR, Abdulamir AS, Vern LS, Abu Bakar F, Abas F, Jahanshiri F, Sekawi Z. Inhibition of growth of highly resistant bacterial and fungal pathogens by a natural product. Open Microbiology Journal, $2011 ; 5 ; 96-106$

Mirza SA, Phelan M, Rimland D, Graviss E, Hamill R, Brandt M E, Gardner T, Sattah M, Ponce de Leon G, Baughman W, Hajjeh RA. The changing epidemiology of cryptococcosis: an update from populationbased active surveillance in 2 large metropolitan areas, 1992-2000. Clinical Infectious Diseases, 2003; 36(6); 789-794.

Moraes EM, Primola NS, Hamdan JS. Antifungal susceptibility of clinical and environmental isolates of Cryptococcus neoformans to four antifungal drugs determined by two techniques. Mycoses, 2003; 46; 164 168

Nakamura CV, Ishida K, Faccin LC, Filho BP, Cortez DA, Rozental S, de Souza W, Ueda-Nakamura T. In vitro activity of essential oil from Ocimum gratissimum L. against four Candida species. Research Microbiology, 2004; 155(7); 579-586.

Oliveira RAG, Lima EO, Vieira WL, Freire KRL, Trajano VN, Lima IO, Souza EL, Toledo MS, Silva-Filho RN. Estudo da interferência de óleos essenciais sobre a atividade de alguns antibióticos usados na clínica. Revista Brasileira de Farmacognosia, 2006; 16(1); 77-82.

Ozcan B, Esen M, Sangun MK, Coleri A, Caliskan M. Effective antibacterial and antioxidant properties of methanolic extract of Laurus nobilis seed oil. Journal of Environmental Biology, 2010; 31(5); 637-641.

Patrakar R, Mansuriya M, Patil P. Phytochemical and Pharmacological Review on Laurus nobilis. International Journal of Pharmaceutical and Chemical Sciences, 2012; 1(2); 595-602.

Pfaller MA, Rinaldi MG,GalgianiJN,BartlettMS, Body BA, Espinel-Ingroff A, Fromtling RA, Hall GS, Hughes CE, Odds FC, Sugar AM.Collaborative Investigation of Variables in Susceptibility Testing of Yeasts. Antimicrobial Agentsand Chemotherapy,1990; 34(9); 1648-1654.

Pereira FO, Wanderley PA, Viana FAC, Lima RB, Sousa FB, Lima EO. Growth inhibition and morphological alterations of Trichophyton rubrum induced by essential oil from Cymbopogon winterianus Jowitt ex bor. Brazilian Journal of Microbiology, 2011; 42(1); 233-242.

Prabuseenivasan S, Jayakumar M, Ignacimuthu S. In vitro antibacterial activity of some plant essential oils. BMC Complementary and Alternative Medicine, 2006; 6(39); 1-8.

Pukkila-Worley R, Mylonakis E. Epidemiology and management of cryptococcal meningitis: developments and challenges. Expert Opinion on Pharmacotherapy, 2008; 9(4); 551-560.

Riaz M, Ashraf C, Chaudhary F. Studies of the essential oil of the Pakistani Laurus nobilis Linn in different seasons. Pakistan Journal Science Industrial Research, 1989; 32, p. 33- 35, 1989.

Rizi MV. Phenological Variation of Laurus nobilis essentials oil from IRAN. Electronic Journal of Environmental, Agricultural and Food Chemistry, 2008; 7(11); 3321-3325.
Rosa A, Assunta M. Extraction and Separation of Volatile and Fixed Oils from Berries of Laurus nobilis L. by Supercrital $\mathrm{CO}_{2}$. Molecules, 2008; 13; 1702-1711.

Saad A, Fadli M, Bouaziz M, Benharref A, Mezrioui NE, Hassani L. Anticandidal activity of the essential oils of Thymus maroccanus and Thymus broussonetii and their synergism with amphotericin B and fluconazol. Phytomedicine, 2010; 17(13); 1057-1060.

Saag MS, Graybill RJ, Larsen RA, Pappas PG, Perfect JR, Powderly WG, Sobel JD, Dismukes WE. Practice guidelines for the management of cryptococcal disease. Clinical Infectious Diseases, 2000; $30(4) ; 710-718$.

Sartoratto A, Machado ALM, Delarmelina C, Figueira GM, Duarte MCT, Rehder VLG. Composition and antimicrobial activity of essential oils from aromatic plants used in Brazil. Brazilian Journal of Microbiology, 2004; 35(4); 275-280.

Singh N, Dromer F, Perfect JR, Lortholary O. Cryptococcosis in solid organ transplant recipients: current state of the science. Clinical Infectious Diseases, 2008; 47(10);1321-1327.

Siqui AC, Sampaio ALF, Sousa MC. Óleos essenciais potencial anti-inflamatório. Biotecnologia, Ciência e Desenvolvimento, $2000 ; 16 ; 38-43$.

Souza EL, Stamford TLM, Lima EO, Trajano VN. Effectiveness of Origanum vulgare L. essential oil to inhibit the growth of food spoiling yeasts. Food Control, 2007; 18; 409-413.

Tempone AG, Sartorelli P, Teixeira D, Prado FO; Calixto IARL, Lorenzi $\mathrm{H}$, Melhem MSC. Brazilian flora extracts as source of novel antileishmanial and antifungal compounds. Memórias do Instituto Oswaldo Cruz, 2008; 103(5); 443-449.

Trajano VN, Lima EO, Souza EL, Travassos ERA. Inhibitory effect of the essential oil from Eugenia carophyllata Thum leaves on coalho chesse contaminating microorganisms. Ciência e Tecnologia de Alimentos, 2010; 30(4); 1001-1006.

Vanden Bossche H, Dromer F, Improvisi I, Lozano-Chiu M, Rex JH, Sanglard D. Antifungal drug resistance in pathogenic fungi. Medical Mycology, 1998; 36; 119-128.

Yalçin H, Anik M, Sanda MA, Cakir A. Gas chromatography/mass spectrometry analysis of Laurus nobilis essential oil composition of northern Cyprus. Journal of Medical Food, 2007; 10(4); 715- 719 .

\section{How to cite this article:}

Pinheiro LS, Filho AAO, Guerra FQS, Menezes FP, Santos SG, Sousa JP, Dantas TB, Lima EO. Antifungalactivity of the essential oil isolated from Laurus nobilis L. against Cryptococcus neoformans strains. J App Pharm Sci, 2017; 7 (05): 115-118. 